\title{
Early-onset diabetes: an epidemic in China
}

\author{
Jiemin Pan, Weiping Jia (凶) \\ Department of Endocrinology and Metabolism, Shanghai Jiao Tong University Affiliated Sixth People's Hospital, Shanghai Clinical Center \\ for Diabetes, Shanghai Diabetes Institute, Shanghai 200233, China \\ (C) The Author(s) 2018. This article is published with open access at link.springer.com and journal.hep.com.cn
}

\begin{abstract}
Although type 2 diabetes is a disease often associated with aging, the global prevalence of early-onset diabetes has been increasing due to man's sedentary lifestyle, low-physical activity, obesity, and some nonmodifiable risk factors. Many studies have found that individuals with early-onset type 2 diabetes were at higher risk of developing vascular complications than those with late-onset diabetes. Individuals with early-onset diabetes are usually unwilling to visit hospital and have more confidence in their health, which results in poor glycemic control and the delayed detection of diabetes-related complications. Few studies have focused on the treatment and prevention of complications in specific population of individuals with early-onset type 2 diabetes. Therefore, focusing on this particular population is critical for the government and academic societies. Screening for T2DM is imminent for young adults with a family history of diabetes, obesity, markers of insulin resistance, or alcohol consumption. More data are definitely required to establish a reasonable risk model to screen for early-onset diabetes.
\end{abstract}

Keywords diabetes; early-onset; diabetes complications

\section{Introduction}

Diabetes is a metabolic disorder that has been increasing worldwide. Over $10 \%$ of Chinese adults were diagnosed with diabetes in 2010, suggesting the rapid growth of this disease in China [1]. Aging has been reported as an important element associated with type 2 diabetes mellitus (T2DM); however, the age at diagnosis has gradually decreased recently [2-4]. A huge increase in the incidence of early-onset T2DM has become a new trend all over the world. According to a large-scale survey in Chinese mainland, the percentages of adults reported with diabetes and prediabetes are $5.7 \%$ and $44 \%$, respectively, among adults younger than 40 years old [5]. In this review, we describe the pathophysiology and characteristics of earlyonset type 2 diabetes and its relationship with the risks for microvascular and macrovascular complications.

Received April 6, 2017; accepted July 19, 2018

Correspondence: Weiping Jia,wpjia@sjtu.edu.cn

\section{The epidemiology of early-onset diabetes}

Most of the evidence for an epidemic of T2DM in younger people originate from western countries. Between 1990 and 2000, New York experienced a 10-fold increase in T2DM in children [6]. The UK has witnessed similar increases in early-onset T2DM, accounting for 5\% of the diabetes population under $<30$ years of age in 2003, increasing to $12 \%$ by 2006 [7], and extending to $24 \%$ of the diabetes population under $<40$ years of age [8]. A higher proportion of early-onset diabetes has been observed to be highly prevalent in Asian countries [1,9]. In a study conducted in 2001 among 9243 patients from 194 primary care centers across Asia, the proportion of T2DM patients diagnosed before the age of 30 varied from $0.5 \%$ in Taiwan (China) and $1.5 \%$ in Korea to $5.4 \%$ in the Philippines [10]. From 1994 to 2000, China experienced an $88 \%$ increase in the prevalence of diabetes in a nationally represented population aged 35-44 years from an InterASIA study [11]. The updated prevalence of prediabetes in 2013 was significantly higher than that in $2010(28.8 \%$ vs. $9.0 \%$ ) among adults younger than 40 years old. The $3.2 \%$ prevalence of diabetes in 2010 increased to $5.8 \%$ by 2013 in a population with younger 
than 40 years $[5,12]$. These reports further supported the hypothesis that early-onset diabetes is becoming one of the major health burdens in China.

\section{Risk factors of early-onset diabetes}

The development of early-onset T2DM represents a complex interaction between genetic and environmental factors. Table 1 summarizes the risk factors for developing early-onset T2DM. In general, the risk factors for earlyonset T2DM are similar to those for late-onset T2DM, which includes rapid transitions from energy scarcity to energy abundance, physical activity to sedentary lifestyles, and a disease pattern dominated by infection to noncommunicable disease, with the additional risks factors of male sex and puberty. These factors can lead to biological, psychological, and behavioral maladaptation, possibly with a genetic or epigenetic basis.

Table 1 Risk factors for early-onset type 2 diabetes

\begin{tabular}{ll}
\hline Modifiable & Non-modifiable \\
\hline Obesity & Ethnicity (Han, Manchu) \\
Low physical activity & Family history of T2DM \\
High sedentary behavior & Puberty \\
Socioeconomic status & Low birth weight \\
& Male sex \\
& Intrauterine hyperglycemia \\
& Previous gestational diabetes \\
\hline
\end{tabular}

Obesity is the major risk factor of early onset diabetes. Surveys in the UK have shown that the major population with early onset T2DM are obese (80\%-92\%) compared with merely $56 \%$ of older adults $[13,14]$, in addition to an adverse linear relationship between BMI and the age at diagnosis of T2DM [15]. With China having undergone shift in economic development over the last few decades, the prevalence of overweight and obese individuals has increased by $414 \%$ in China from $3.7 \%$ in 1982 to $19.0 \%$ in 2002 [16]. Consequently, metabolic syndrome has gotten increasingly prevalent at an alarming rate and is about to contribute to the annual 9 million deaths from cardiovascular diseases by 2030 [17]. The main factor driving the obesity epidemic is the rapid nutrition transition occurring in the last few decades, that is, the shift to higher fat and lower carbohydrate content in the diet, as well as increased intake of foods from animal sources, edible oils, and added sugars [18]. In China, the intake of dietary fat rose from $19.3 \%$ in 1989 to $27.3 \%$ in 1997 [19]. In conclusion, obesity has become common and contributed greatly to the prevalence of early-onset diabetes in China.

Substantial differences are present in genes, culture, socioeconomic levels, climate, lifestyle, and geographical features of residential area among ethnic groups. Worldwide, Japanese, Hispanics, and Native Americans have the highest risks of developing T2DM in childhood [20-23]. China has 56 ethnic groups, in which Chinese Han is the majority. Compared with Han participants, most major minority ethnic groups, except for Manchu participants, had a significantly lower prevalence of both total diabetes and prediabetes [5]. Tibetan highlanders have been shown to have accelerated vulnerability to diabetes with lifestyle change or aging [24]. However, data for the ethnic variation in early-onset diabetes prevalence is difficult to determine from the cross-sectional survey. Further investigation is required.

In Chinese mainland, a population-based cross-sectional study has found that a higher proportion of males is included in newly diagnosed early-onset diabetes participants compared with those who had diabetes onset at 53 years or later [25]. A recent analysis of the "National Health Insurance database" from Taiwan noted that the prevalence of diagnosed diabetes among those aged 20-39 has increased by $15 \%$ (from 0.45 to 0.5 ) for women and $54 \%$ (from 0.52 to 0.78 ) for men during 2000-2008 [26]. A large population-based study reported that the prevalence of diabetes has become significantly higher among men than in women, but the prevalence of prediabetes does not differ significantly according to sex [12].

Intrauterine environment and gestational diabetes mellitus (GDM) play parts in the development of early-onset diabetes. A study has indicated that apart from genetic factors, intrauterine environment can play an important part in the evolution of $\beta$ cell dysfunction and insulin resistance, which then increase the risk of obesity, T2DM, and cardiovascular disease later in life [27,28]. The mechanism is thought to be mediated by heritable alterations in gene expression rather than variation in DNA sequence, but involve epigenetic modifications, such as DNA methylation and histone modification [29]. Statistics approved of this conclusion. In a Chinese study, offspring whose mothers were exposed to famine had increased risk of diabetes or hyperglycemia in adulthood, especially when the offspring was brought up in a nutrient-rich urban environment [30]. An Indian survey showed that an offspring with experienced intrauterine hyperglycemia was found to be connected with increased risk of diabetes and obesity [31]. Chinese specialists reported that offspring (aged 8-10 years) of mothers with GDM tended to have higher blood pressure and more inverse cardio-metabolic profile than peers with normoglycemic mothers [32]. Women with a history of GDM were at a sevenfold increased risk of diabetes later in their lives [33]. Thus, a vicious cycle of diabetes begetting diabetes exists; this cycle calls for imminent concern in 
China in driving the escalating epidemic of early-onset diabetes.

\section{Etiology of early-onset diabetes}

Early-onset diabetes usually refers to diabetes that develops in adults less than 40 years old. Although this population may include latent autoimmune diabetes in adults (LADA) and individuals with classic type 1 diabetes, these two conditions can be ignored because they are both rare conditions in China. Moreover, classic type 1 diabetes is characterized with a clinical feature of abrupt onset and classic symptoms such as polydipsia, polyuria, weight loss, and ketonuria or ketoacidosis.

The pathophysiology of early-onset type 2 diabetes is related to multiple factors, including genetic, socioeconomic, psychological, and behavioral factors. The consultation rate of individuals with early-onset diabetes is lower due to less free time and more assurance in their physical condition with the absence of typical symptoms. Ignoring the progression of diabetes would cause worse metabolic control and exacerbate the reduced $\beta$ cell function. Clinical decision-making relies heavily on understanding the pathophysiology of early-onset diabetes. However, it is hard to compare the $\beta$ cell function between individuals with newly diagnosed early-onset diabetes and those with late-onset diabetes for lack of population-based studies. Few studies were concerned about the pathophysiological and genetic factors that may be related to newly diagnosed early-onset diabetes.

Generally, common Maturity Onset Diabetes of the Young (MODY) gene mutations are not the etiology of early-onset type 2 diabetes. A Spanish study stated that the T130I variant in HNF4A is a major susceptibility genotype associated with early-onset type 2 diabetes in an individual from central Spain [34]. Six known MODY genes, namely, $H N F-4 \alpha, G C K, H N F-1 \alpha, I P F-1, H N F-1 \beta$, and NeuroD1 were screened, and a small percentage of Thai subjects with early-onset type 2 diabetes (10\%) presented with changes in these six MODY genes [35]. However, a Mexican study also indicated that these variants would not necessarily cause early-onset diabetes under normal circumstances [36]. Therefore, many genes are still to be identified in most early-onset type 2 diabetes subjects. In diabetic Asian patients, family history of diabetes and low body mass index (BMI) have both been reported to be related to poor pancreatic function [3]. Genetic factors, together with the possible pathogenic role of epigenetics (which may affect $\beta$ cell development in individuals with a family history of diabetes), might play a particularly important role in early-onset diabetes.

A Chinese study compared insulin resistance and $\beta$ cell function in individuals with early- and late-onset diabetes. The early-onset diabetes group showed increased first- phase insulin release but similar late-phase insulin release compared with individuals with late-onset diabetes. The study also demonstrated that when age-matched healthy subjects were used as reference, the magnitude of $\beta$ cell dysfunction was greater in those with early-onset diabetes than in those with middle-aged-onset and late-onset diabetes. The study also compared the characteristics of participants with early-onset diabetes with those of their healthy aged-matched peers in the appropriate context. In accordance with previous findings, a more rapid decline of $\beta$ cell function is suggested in subjects with early-onset diabetes than in subjects with late-onset diabetes [37]. Accelerated switch from oral anti-diabetes medications to insulin injections may occur when $\beta$ cell function declines rapidly in individuals with early-onset diabetes. The findings explained the reason for higher insulin injection rate in individuals with early-onset diabetes even after adjusting for the disease duration [25].

Type 1 diabetes mellitus (T1DM) is characterized by having a more progressive deterioration of $\beta$ cell function compared with T2DM. Individuals with T2DM possibly have prolonged asymptomatic disease. The onset is usually abrupt in T1DM; however, it is insidious, asymptomatic and can go undiagnosed for several years in T2DM. Compared with T1DM patients, one factor that contributed to the higher risk of microvascular complications in T2DM patients is their less intensive glycemic control in a durable period. According to the Diabetes Control and Complications Trial (DCCT), UK Prospective Diabetes Study (UKPDS), and Action in Diabetes and Vascular Disease: Preterax and Diamicron Controlled Evaluation (ADVANCE) [38-40] studies, the risk of microvascular complications can be reduced when patients achieve more intensive glycemic control. T2DM patients having higher complication rates despite better lipid control and similar blood pressure suggests a more aggressive feature in earlyonset T2DM than T1DM [41].

Socioeconomic, psychological, and behavioral factors (including less physical work and dietary changes) contribute to the pathophysiology of early-onset type 2 diabetes. From a behavioral perspective, a young adult with diabetes is more likely to have increased stress, depressive symptoms, and poor self-management [42]. Young patients usually have higher default rates and poorer medication compliance than older patients, which may be due to competing priorities such as accumulation of wealth and raising a family [43]. Although individuals with earlyonset diabetes are more likely to receive formal diabetes education than those with late-onset diabetes, they are less likely to have a healthy lifestyle and aggressively manage their disease [44]. Additionally, physicians might feel hesitant to prescribe multiple lifelong drugs to young patients due to the uncertainty of the long-term side-effects, especially in women of childbearing age [45]. 


\section{Characteristics of early-onset diabetes}

Since the early 21 st century, some national clinical studies have examined the increasing prevalence of early-onset diabetes as well as the characteristics associated with earlyonset diabetes and compared the results with those of classic type 1 diabetes or late-onset diabetes.

A cross-sectional, retrospective study in Korea compared the clinical characteristics of early- and late-onset diabetes. In comparison with late-onset diabetic patients, individuals with early-onset diabetes are characterized with higher glycated hemoglobin (HbAlc), fasting glucose, postprandial glucose levels, and more reports of a family history, typical symptoms, microalbuminuria, as well as implementation of insulin therapy as the initial treatment [46].

Two studies in hospital settings in Western and Asian countries indicated that early-onset diabetes patients had a more extensive family history of diabetes, as well as a higher BMI and elevated $\mathrm{HbAlc}$ and low-density lipoprotein cholesterol (LDL-C) level [44,47]. A largescale hospital-based study in Chinese mainland suggested that individuals with early-onset diabetes had lower systolic blood pressure (SBP), lower LDL-C, higher $\mathrm{HbA1c}$, and similar BMI and triglyceride levels than individuals with late-onset diabetes [5]. The two results differed among the hospital-based studies, which may be attributed to inevitable selection bias, especially when electing control subjects among healthy participants in the hospital system.

A national cross-sectional study investigated the characteristics of Chinese individuals newly diagnosed with early-onset diabetes; 2801 subjects newly diagnosed with diabetes and without known diabetes or pre-diabetes were enrolled. This large, multi-center, cross-sectional, population-based study revealed that the incidence of early-onset diabetes among newly diagnosed patients was $23.3 \%$. This result is consistent with the China Non-Communicable Disease Surveillance Survey, another large populationbased study conducted in 2010, concluding that the percentage of participants aged 18-40 years was $15.7 \%$ among all newly diagnosed diabetes cases, as determined by the oral glucose tolerance test (OGTT) [1]. This result is much higher than the International Diabetes Federation (IDF)-predicted values in Australia, the UK, and Japan [41]. The 2010 study also found that the early-onset diabetes group had lower SBP (levels of total cholesterol, low-density lipoprotein cholesterol, and 2-hour postprandial blood glucose) and urinary albumin creatinine ratio. No difference was found in the BMI and family history of diabetes between the early-onset diabetes subjects and any other age groups. Homeostasis model assessment of insulin resistance (HOMA-IR) is one of the most extensively used methods for evaluating insulin resistance in epidemiological studies, and insulin resis- tance assessed by HOMA-IR was independently positively associated with age in newly diagnosed diabetes. The early-onset diabetes group had an increased HOMA-IR and disposition index 30 minutes after glucose load. The decline in $\beta$ cell function was more pronounced in individuals with early-onset diabetes. An increased insulin resistance and more severe $\beta$ cell failure can be found in diabetic individuals at a younger age [37].

Patients with early-onset diabetes were less likely to meet treatment goals. In an American study, patients younger than 40 years with type 2 diabetes and an $\mathrm{HbA} 1 \mathrm{c}$ concentration greater than $6.5 \%$ had a 3.8 -fold increased risk of death before the age of 55 years compared with individuals with an $\mathrm{HbA} 1 \mathrm{c}$ concentration below $5.7 \%$ after adjusting for sex and ethnic origin [48]. The Joint Asia Diabetes Evaluation (JADE) program also found that young age at the time of diagnosis remained independently associated with poor glycemic control even after adjusting for major confounders. This conclusion was consistent across all countries despite the wide variability of clinical practices, health-care systems, and coverage for insurance and medication and also suggested that other mechanisms such as genetic, socioeconomic, psychological, or behavioral factors were involved [44].

\section{Early-onset diabetes and microvascular disease}

Diabetic retinopathy (DR) is the most common microvascular complication of diabetes and results from retinal vascular damage due to poor glycemic control and prolonged duration of unregulated diabetes. DR is more aggressive and accelerated in T1DM. The onset of T1DM is usually abrupt, whereas in T2DM, it is asymptomatic and can go undiagnosed for several years. Many researchers and scholars have focused on the microvascular complications associated with early-onset diabetes and provided us more incontrovertible data.

The JADE cohort compared clinical characteristics, metabolic risk factors, and the prevalence of complications between participants with early- and late-onset diabetes in subjects with type 2 diabetes selected from 245 outpatient clinics in nine Asian countries or regions. In this clinicbased setting across Asia, one in five adult patients had early-onset diabetes, and patients with early-onset diabetes had higher mean concentrations of $\mathrm{HbAlc}$ and a higher prevalence of retinopathy than those with late-onset diabetes. In comparison with patients with late-onset diabetes, patients with early-onset diabetes had poorer metabolic control, and few received organ-protective drugs [44].

With 29442 patients of T2DM from 77 tertiary hospitals enrolled, a Chinese mainland cross-sectional survey analyzed the prevalence and risk factors of diabetic 
retinopathy in China. According to the result, a total of 3192 (11.2\%) individuals less than 40 years old were diagnosed with diabetes. The occurrence of microvascular complications in early-onset diabetes is substantially higher than late-onset diabetes (nephropathy: $5.1 \%$ vs. $1.5 \%$; retinopathy: $7.1 \%$ vs. $2.7 \%$ ). Age and sex were adjusted to evaluate the risk of developing microvascular diseases in T2DM, which showed a 1.69-fold higher risk in patients with early-onset T2DM than those with late-onset T2DM [49].

A cross-sectional study in Sri Lanka evaluated the rate of DR and its risk factors among young adult patients with diabetes. The study found out that the percentage of patients with early-onset diabetes diagnosed with retinopathy reaches nearly $20 \%$. Factors including age, duration of diabetes, HbAlc, and urinary albumin levels play an important role in the presence of retinopathy, and among them, HbA1c was remarkably related to its severity [50].

The study by Treatment Options for Type 2 Diabetes in Adolescents and Youth (TODAY) was the first prospective study to assess the complications and comorbidities of T2DM in an adolescent population. This study reported that the presence of hypertension was increased from $11.6 \%$ to $33.8 \%$ as time went from the baseline to the end of the study. During this period, the risk for elevated LDLC levels rose from $4.5 \%$ to $10.7 \%$. Microalbuminuria was found in $6.3 \%$ of the cohort at baseline but grew up to $16.6 \%$ at the end of the study. Retinopathy was present in $13.9 \%$ of individuals in the TODAY cohort by the end of the study [51].

A cross-sectional study in India also screened the vascular complications in individuals newly diagnosed with early-onset type 2 diabetes and found that DR, neuropathy, and nephropathy were observed in $5.1 \%$, $13.2 \%$, and $0.9 \%$, respectively, of the individuals [52] (Table 2). This study reiterated that screening for complications of newly diagnosed diabetes even in young population is important, as recognizing and aggressively treating complications and their associated risk factors can decelerate the development of these complications. Another clinical study in India also compared the prevalence and risk factors for DR in Indians with early-onset type 1 and type 2 diabetes. The results showed that the prevalence of DR was $53.3 \%$ among individuals with T1DM and 52.7\% among those with T2DM. The study performed the multivariable logistic regression analysis and found that diabetes duration $(\mathrm{OR}=$ 1.99), waist circumference ( $\mathrm{OR}=1.28)$, and microalbuminuria $(\mathrm{OR}=2.39)$ were associated with $\mathrm{DR}$ in early-onset T1DM. Diabetes duration $(\mathrm{OR}=2.21)$, diastolic blood pressure $(\mathrm{OR}=1.54)$, glycated hemoglobin $(\mathrm{OR}=1.37)$, and lower stimulated c-peptide $(\mathrm{OR}=1.54)$ were associated with DR in early-onset T2DM [53].

Only a few prospective studies that compare the incidence of DR among individuals with early-onset and late-onset type 1 or type 2 diabetes have been carried out. A prospective Indian study with median follow-up of 5 years was carried out to compare the incidence of complications among individuals with type 1 or type 2 early-onset diabetes. In total, 108 subjects with T1DM and 90 subjects with T2DM were enrolled. The incidence of micro- and macro-complications reported in numbers/1000 person-years of follow-up of T1DM and T2DM were as follows: retinopathy, 77.4 versus $78.0 / 1000$ person-years; nephropathy, 62.0 versus 58.8; neuropathy 7.8 versus 13.9 and ischemic heart disease, 1.2 versus 5.4. In the Cox regression analysis with the adjustment for age, HbAlc, SBP, and serum cholesterol, T2DM subjects had a 2.11fold higher risk of developing any diabetes-related vascular complication than T1DM subjects [40]. Notably, T2DM with early onset would have more adverse consequence, especially macro-vascular complications than T1DM.

The leading cause of end-stage renal disease in China is diabetic nephropathy, and the prevalence of diabetic nephropathy is continuously increasing with the increasing prevalence of diabetes. Albuminuria is a marker known to be used in the assessment of the early period of diabetic nephropathy. The JADE clinical study demonstrated that early-onset T2DM had a much higher incidence of renal complications than late-onset T2DM; this incidence was even higher than that among patients with T1DM [44]. Some small-sample cross-sectional data from individuals with early-onset T2DM suggested that the percentage of patients developed with microalbuminuria within 10 years of diagnosis ranged from $18 \%$ to $72 \%$, and the progression rates of incidence and development of nephropathy were similar between T1DM and T2DM [54]. In an Australian cohort of adolescents with early-onset T2DM, around 45\% of subjects had abnormally elevated urinary albumin levels [55]. In another group of 68 Australian adolescents with T2DM, the percentage of the group with microalbuminuria is $7 \%$, which increased to $28 \%$ over an approximately 2 year period [56]. In a cohort of 105 early-onset T2DM in New Zealand, the percentage of individuals developing microalbuminuria added up to $72 \%$ in 3 years' time [57]. From the SEARCH study, 22\% of T2DM subjects with an average age of 16.2 years and diabetes duration of 1.9 years had abnormal albumin-to-creatinine ratios [58]. However, very few studies have assessed the longitudinal progression of renal disease in early-onset T2DM despite these alarming cross-sectional data.

\section{Early-onset diabetes and macrovascular diseases}

Cardiovascular disease is a leading killer in most developed countries, as well as in many developing countries. Unlike patients with late-onset diabetes, 
individuals with early-onset type 2 diabetes seem to be at higher risk of cardiovascular complications and more aggressive progression of vascular complications. Although cardiovascular risk factors are similar between early-onset and late-onset diabetes, individuals with earlyonset diabetes would be exposed to these risk factors much longer than those with late-onset diabetes due to longer life expectancies. In fact, the progression of atherosclerosis is affected by the same multiple factors, including smoking, hypertension, obesity, and dyslipidemia in young and older individuals [59]. Prolonged duration of diabetes might result in decreased $\beta$ cell function, elevated oxidative stress, and activation of the renin-angiotensin system, which then could cause the rise of LDL-C and SBP levels. Thus, the risk of cardiovascular disease was raised a lot owing to the long-lasting duration of diabetes and exacerbated metabolic factors.

An Australian prospective study compared long-term clinical outcomes and survival between early-onset type 2 and type 1 diabetes and found that early-onset T2DM had a significant increase in mortality with an increased hazard for death $(\mathrm{HR}=2.0)$. More individuals with early-onset T2DM died due to cardiovascular-related events [60] (Table 2). A clinical study from Hong Kong also showed that early-onset T2DM had a remarkably increased incidence of cardiovascular complications compared with patients with late-onset diabetes. In an around 10000 Chinese T2DM cohort, more than $20 \%$ had early-onset diabetes with a median follow-up period of 7.5 years. Patients with early- or late-onset diabetes shared similar risk factors despite a 20-year gap in age. For the same disease duration, patients with early-onset diabetes had lower incidence of cardiovascular disease but higher cumulative rates of clinical events at any given age. For patients with early-onset diabetes at any age, the increased risk for cardiovascular-renal complications is likely to be due to longer disease duration [61]. A cross-sectional study in Mexico evaluated the cardiovascular surrogate including carotid intima-media thickness, atherosclerotic plaques at the carotid level, and ankle-arm index between early- and late-onset type 2 diabetes. The number of early-onset T2DM with atheroma plaque almost doubled compared with the late-onset group (10.4\% vs. $6.1 \%$, respectively) [62].

A cross-sectional study also conducted in India determined the prevalence of macrovascular complications in patients newly diagnosed with early-onset diabetes. As a result, ischemic heart disease, peripheral vascular disease, and stroke were found to be presented in $0.7 \%, 2 \%$, and $0.1 \%$, respectively, of all enrolled subjects [63].

Another large-scale cross-sectional multi-center survey was conducted in 2012 using data from the China National HbA1c Surveillance System, which included more than 2 million Chinese T2DM patients. After adjusting for age, higher prevalence of non-fatal cardiovascular disease can be found in patients with early-onset diabetes than lateonset $(11.1 \%$ vs. $4.9 \%$; $P<0.001)$. Patients with earlyonset type 2 diabetes were at higher risk of developing non-fatal cardiovascular disease than those with late-onset type 2 diabetes after the adjustment of age and sex (OR = 1.91). When the duration of diabetes was adjusted, the effect size for the risk of non-fatal cardiovascular diseases was significantly attenuated $(\mathrm{OR}=1.13)$. Consequently, the longer duration of diabetes may contribute a lot to an increased risk of cardiovascular disease [4].

A longitudinal study of 4045 men aged 60 to 79 years old with a mean follow-up of 9 years was conducted to examine the influence of age at onset and diabetes duration on the risk of cardiovascular disease and all-cause mortality. Early- and late-onset diabetes were concluded to increase the risk of major coronary heart disease (CHD) events and mortality, but early-onset diabetes appeared to be a CHD equivalent factor when the disease duration exceeded 10 years [64].

Table 2 The prevalence of macrovascular and microvascular complications among individuals with early-onset diabetes

\begin{tabular}{|c|c|c|c|}
\hline & 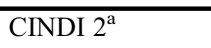 & MI Constantino ${ }^{b}$ & $\mathrm{JADE}^{\mathrm{c}}$ \\
\hline Diabetes duration & Newly diagnosed & 11.6 & 10 \\
\hline Neuropathy & 13.2 & & 11 \\
\hline Retinopathy & 5.06 & 37 & 20 \\
\hline Nephropathy & 0.93 & & 10 \\
\hline Microalbuminuria & & 47.4 & \\
\hline Ischemic heart disease & 0.66 & 2.5 & 5 \\
\hline Peripheral vascular disease & 2 & 14.4 & 7 \\
\hline Cerebrovascular disease & 0.13 & 4.3 & 2 \\
\hline
\end{tabular}

${ }^{a}$ Cardiovascular risk factors, micro- and macrovascular complications at diagnosis in patients with young onset type 2 diabetes in India: CINDI 2. Indian $\mathrm{J}$ Endocrinol Metab 2016; 20(1): 114-118.

${ }^{\mathrm{b}}$ Long-term complications and mortality in young-onset diabetes: type 2 diabetes is more hazardous and lethal than type 1 diabetes. Diabetes Care 2013; 36(12): 3863-3869.

${ }^{\mathrm{c}}$ Metabolic profiles and treatment gaps in young-onset type 2 diabetes in Asia (the JADE program): a cross-sectional study of a prospective cohort. Lancet Diabetes Endocrinol 2014; 2(12): 935-943. 


\section{Treatment and prevention}

Few studies have focused on the treatment of specific population of individuals with early-onset type 2 diabetes. Regardless of the elevated prevalence of T2DM among the young adult population, data for appropriate treatment guideline is rare. The TODAY study is the first and only large-scale randomized trial to assess the impact of intensive therapy on individuals with early-onset T2DM. This study was a multi-center, randomized clinical trial with volunteers observed for about 3.86 years on the average. The results showed that metformin monotherapy was related to long-lasting control of glucose in approximately $50 \%$ of children and adolescents with T2DM. The additional supplement of rosiglitazone, instead of an active lifestyle intervention, was superior to metformin alone. These results indicated that the bulk of young people with T2DM may need combined treatments or insulin injection no longer than 5 years after diagnosis [64]. Metformin and insulin are the only drugs approved for use in pediatric patients with T2DM. Moreover, a randomized doubleblinded study revealed the safety of using metformin in 82 individuals aged 10-16 years for up to 16 weeks, with a reduction in HbA1c compared with the placebo group [65]. Another randomized single-blinded study reported a reduction in $\mathrm{HbA} 1 \mathrm{c}$ in 263 young people with T2DM (mean age 13.8 years) using metformin $(-0.54 \%)$ and glimepiride $(-0.71 \%)$, both of which were safe to use within the 26-week follow-up period [66].

Though implementing diabetes-prevention programs among young population is highly important, limited progression has been worked out due to difficulty in distinguishing young adults at risk for T2DM. Considering themselves as sound and healthy, young adults tend to ignore their own vulnerabilities to prediabetes or diabetes and rarely receive diabetes screenings. One study characterized risk factors concerned with type 2 diabetes in Indian-American youth to determine a non-invasive risk model. The risk prediction model finally showed that a direct family history of diabetes, obesity, alcohol consumption, and high fasting glucose level were significantly associated with the onset of prediabetes or diabetes within 5 years. Although this novel non-invasive screening model has the potential to assess the risk of young adults in developing diabetes, it is still needed to be verified in other racial young adults [67].

Studies that focus on the prevention of early onset diabetes are rare. Adjusting obesity and impaired glucose regulation with diet and exercise interventions or pharmacological therapy such as metformin and thiazolidinediones can prevent T2DM [68,69]. A study of US Diabetes Prevention Program operated among 3234 non-diabetic individuals with elevated plasma glucose concentrations showed that lifestyle intervention, including physical activity and weight loss, reduced the risk of type 2 diabetes, where relative risk reduction (RRR) is $58 \%$, which was more effective than metformin (RRR 31\%) or placebo. This benefit could be found in all participant populations including individuals aged 25-44 years [70].

For the sake of preventing micro- and macrovascular complications of diabetes, treatments of hyperglycemia, blood pressure, and lipids were needed in this process [71]. An angiotensin-converting enzyme inhibitor or statin should be taken when hypertension or hyperlipidemia developed [72]. However, we could not find any pharmacotherapeutic outcome studies of such agents in early-onset T2DM.

\section{Conclusions}

China bears the heaviest burden from diabetes and its complications worldwide. Academic societies have implemented actions in diverse aspects and coordinated multilevel activities in China. An elevation in the prevalence of diabetes in China was observed, with much more young population developing diabetes. Plenty of large-scale epidemiological studies have confirmed that early-onset diabetes rapidly raised the incidence of macrovascular and microvascular complications. This increase is mainly due to longer duration of diabetes and unoptimized glycemic control at the beginning of diagnosis. All these findings imply the urgency of taking actions to prevent diabetes, especially in young Chinese adults. This review highlights the steps necessary for the government's establishment of policies aimed at young people to cut down the vascular complications of this disease.

With the high prevalence of macrovascular and microvascular complications of early-onset diabetes, screening cardiovascular risk factors and diabetes-related complications in early-onset diabetes at the time of diagnosis is crucial.

In conclusion, the majority of early-onset diabetes stay asymptomatic for a long period. Thus, screening for T2DM is imminent for young adults with a family history of diabetes, obesity, markers of insulin resistance, or alcohol consumption. More data are definitely required to establish a reasonable risk model to screen for early-onset diabetes.

\section{Compliance with ethics guidelines}

Jiemin Pan and Weiping Jia have no conflict of interest to declare. This manuscript is a review article and does not involve a research protocol requiring approval by the relevant institutional review board or ethics committee.

Open Access This article is distributed under the terms of the Creative Commons Attribution 4.0 International License (http:// creativecommons.org/licenses/by/4.0/), which permits unrestricted use, distribution, and reproduction in any medium, provided the 
appropriate credit is given to the original author(s) and the source, and a link is provided to the Creative Commons license, which indicates if changes are made.

\section{References}

1. Xu Y, Wang L, He J, Bi Y, Li M, Wang T, Wang L, Jiang Y, Dai M, Lu J, Xu M, Li Y, Hu N, Li J, Mi S, Chen CS, Li G, Mu Y, Zhao J, Kong L, Chen J, Lai S, Wang W, Zhao W, Ning G; 2010 China Noncommunicable Disease Surveillance Group. Prevalence and control of diabetes in Chinese adults. JAMA 2013; 310(9): 948-959

2. Chan JC, Malik V, Jia W, Kadowaki T, Yajnik CS, Yoon KH, Hu FB. Diabetes in Asia: epidemiology, risk factors, and pathophysiology. JAMA 2009; 301(20): 2129-2140

3. Ma RC, Chan JC. Type 2 diabetes in East Asians: similarities and differences with populations in Europe and the United States. Ann N Y Acad Sci 2013; 1281(1): 64-91

4. Huo X, Gao L, Guo L, Xu W, Wang W, Zhi X, Li L, Ren Y, Qi X, Sun Z, Li W, Ji Q, Ran X, Su B, Hao C, Lu J, Guo X, Zhuo H, Zhang D, Pan C, Weng J, Hu D, Yang X, Ji L. Risk of non-fatal cardiovascular diseases in early-onset versus late-onset type 2 diabetes in China: a cross-sectional study. Lancet Diabetes Endocrinol 2016; 4(2): 115-124

5. Wang L, Gao P, Zhang M, Huang Z, Zhang D, Deng Q, Li Y, Zhao Z, Qin X, Jin D, Zhou M, Tang X, Hu Y, Wang L. Prevalence and ethnic pattern of diabetes and prediabetes in China in 2013. JAMA 2017; 317(24): 2515-2523

6. Grinstein G, Muzumdar R, Aponte L, Vuguin P, Saenger P, DiMartino-Nardi J. Presentation and 5-year follow-up of type 2 diabetes mellitus in African-American and Caribbean-Hispanic adolescents. Horm Res 2003; 60(3): 121-126

7. Harron KL, Feltbower RG, McKinney PA, Bodansky HJ, Campbell FM, Parslow RC. Rising rates of all types of diabetes in south Asian and non-south Asian children and young people aged 0-29 years in West Yorkshire, U.K., 1991-2006. Diabetes Care 2011; 34(3): 652654

8. Gunathilake W, Song S, Sridharan S, Fernando DJ, Idris I. Cardiovascular and metabolic risk profiles in young and old patients with type 2 diabetes. QJM 2010; 103(11): 881-884

9. Cowie CC, Rust KF, Ford ES, Eberhardt MS, Byrd-Holt DD, Li C, Williams DE, Gregg EW, Bainbridge KE, Saydah SH, Geiss LS. Full accounting of diabetes and pre-diabetes in the U.S. population in 1988-1994 and 2005-2006. Diabetes Care 2009; 32(2): 287-294

10. Chuang LM, Soegondo S, Soewondo P, Young-Seol K, Mohamed M, Dalisay E, Go R, Lee W, Tong-Yuan T, Tandhanand S, Nitiyanant W, The-Trach M, Cockram C, Jing-Ping Y. Comparisons of the outcomes on control, type of management and complications status in early onset and late onset type 2 diabetes in Asia. Diabetes Res Clin Pract 2006; 71(2): 146-155

11. Gu D, Reynolds K, Duan X, Xin X, Chen J, Wu X, Mo J, Whelton PK, He J; InterASIA Collaborative Group. Prevalence of diabetes and impaired fasting glucose in the Chinese adult population: International Collaborative Study of Cardiovascular Disease in Asia (InterASIA). Diabetologia 2003; 46(9): 1190-1198

12. Yang W, Lu J, Weng J, Jia W, Ji L, Xiao J, Shan Z, Liu J, Tian H, Ji Q, Zhu D, Ge J, Lin L, Chen L, Guo X, Zhao Z, Li Q, Zhou Z, Shan
G, He J; China National Diabetes and Metabolic Disorders Study Group. Prevalence of diabetes among men and women in China. N Engl J Med 2010; 362(12): 1090-1101

13. Hsia Y, Neubert AC, Rani F, Viner RM, Hindmarsh PC, Wong IC. An increase in the prevalence of type 1 and 2 diabetes in children and adolescents: results from prescription data from a UK general practice database. Br J Clin Pharmacol 2009; 67(2): 242-249

14. Haines L, Wan KC, Lynn R, Barrett TG, Shield JP. Rising incidence of type 2 diabetes in children in the U.K. Diabetes Care 2007; 30(5): 1097-1101

15. Hillier TA, Pedula KL. Characteristics of an adult population with newly diagnosed type 2 diabetes: the relation of obesity and age of onset. Diabetes Care 2001; 24(9): 1522-1527

16. Asia Pacific Cohort Studies Collaboration. The burden of overweight and obesity in the Asia-Pacific region. Obes Rev 2007; 8(3): 191-196

17. Gu D, Reynolds K, Wu X, Chen J, Duan X, Reynolds RF, Whelton $\mathrm{PK}, \mathrm{He} \mathrm{J}$; InterASIA Collaborative Group. Prevalence of the metabolic syndrome and overweight among adults in China. Lancet 2005; 365(9468): 1398-1405

18. Popkin BM, Horton S, Kim S, Mahal A, Shuigao J. Trends in diet, nutritional status, and diet-related noncommunicable diseases in China and India: the economic costs of the nutrition transition. Nutr Rev 2001; 59(12): 379-390

19. Du S, Lu B, Zhai F, Popkin BM. A new stage of the nutrition transition in China. Public Health Nutr 2002; 5(1A): 169-174

20. Chan JC, Cheung CK, Swaminathan R, Nicholls MG, Cockram CS. Obesity, albuminuria and hypertension among Hong Kong Chinese with non-insulin-dependent diabetes mellitus (NIDDM). Postgrad Med J 1993; 69(809): 204-210

21. Dabelea D, DeGroat J, Sorrelman C, Glass M, Percy CA, Avery C, $\mathrm{Hu}$ D, D'Agostino RB Jr, Beyer J, Imperatore G, Testaverde L, Klingensmith G, Hamman RF; SEARCH for Diabetes in Youth Study Group. Diabetes in Navajo youth: prevalence, incidence, and clinical characteristics: the SEARCH for Diabetes in Youth Study. Diabetes Care 2009; 32(Suppl 2): S141-S147

22. Bell RA, Mayer-Davis EJ, Beyer JW, D’Agostino RB Jr, Lawrence JM, Linder B, Liu LL, Marcovina SM, Rodriguez BL, Williams D, Dabelea D; SEARCH for Diabetes in Youth Study Group. Diabetes in non-Hispanic white youth: prevalence, incidence, and clinical characteristics: the SEARCH for Diabetes in Youth Study. Diabetes Care 2009; 32(Suppl 2): S102-S111

23. Liu LL, Yi JP, Beyer J, Mayer-Davis EJ, Dolan LM, Dabelea DM, Lawrence JM, Rodriguez BL, Marcovina SM, Waitzfelder BE, Fujimoto WY; SEARCH for Diabetes in Youth Study Group. Type 1 and type 2 diabetes in Asian and Pacific Islander U.S. youth: the SEARCH for Diabetes in Youth Study. Diabetes Care 2009; 32 (Suppl. 2): S133-140

24. Okumiya K, Sakamoto R, Ishimoto Y, Kimura Y, Fukutomi E, Ishikawa M, Suwa K, Imai H, Chen W, Kato E, Nakatsuka M, Kasahara Y, Fujisawa M, Wada T, Wang H, Dai Q, Xu H, Qiao H, Ge RL, Norboo T, Tsering N, Kosaka Y, Nose M, Yamaguchi T, Tsukihara T, Ando K, Inamura T, Takeda S, Ishine M, Otsuka K, Matsubayashi K. Glucose intolerance associated with hypoxia in people living at high altitudes in the Tibetan highland. BMJ Open 2016; 6(2): e009728

25. Zou X, Zhou X, Ji L, Yang W, Lu J, Weng J, Jia W, Shan Z, Liu J, 
Tian H, Ji Q, Zhu D, Ge J, Lin L, Chen L, Guo X, Zhao Z, Li Q, Zhou Z. The characteristics of newly diagnosed adult early-onset diabetes: a population-based cross-sectional study. Sci Rep 2017; 7 (1): 46534

26. Jiang YD, Chang CH, Tai TY, Chen JF, Chuang LM. Incidence and prevalence rates of diabetes mellitus in Taiwan: analysis of the 2000-2009 Nationwide Health Insurance database. J Formos Med Assoc 2012; 111(11): 599-604

27. Barker DJ, Gluckman PD, Godfrey KM, Harding JE, Owens JA, Robinson JS. Fetal nutrition and cardiovascular disease in adult life. Lancet 1993; 341(8850): 938-941

28. Gluckman PD, Hanson MA, Cooper C, Thornburg KL. Effect of in utero and early-life conditions on adult health and disease. N Engl J Med 2008; 359(1): 61-73

29. Gluckman PD, Hanson MA, Buklijas T, Low FM, Beedle AS. Epigenetic mechanisms that underpin metabolic and cardiovascular diseases. Nat Rev Endocrinol 299; 5(7): 401-408

30. Li Y, He Y, Qi L, Jaddoe VW, Feskens EJ, Yang X, Ma G, Hu FB. Exposure to the Chinese famine in early life and the risk of hyperglycemia and type 2 diabetes in adulthood. Diabetes 2010; 59 (10): 2400-2406

31. Dabelea D, Hanson RL, Lindsay RS, Pettitt DJ, Imperatore G, Gabir MM, Roumain J, Bennett PH, Knowler WC. Intrauterine exposure to diabetes conveys risks for type 2 diabetes and obesity: a study of discordant sibships. Diabetes 2000; 49(12): 2208-2211

32. Tam WH, Ma RC, Yang X, Ko GT, Tong PC, Cockram CS, Sahota DS, Rogers MS, Chan JC. Glucose intolerance and cardiometabolic risk in children exposed to maternal gestational diabetes mellitus in utero. Pediatrics 2008; 122(6): 1229-1234

33. Kim C, Newton KM, Knopp RH. Gestational diabetes and the incidence of type 2 diabetes: a systematic review. Diabetes Care 2002; 25(10): 1862-1868

34. Cieza-Borrella C, Díaz-Soto G, Martínez-Pino I, Puig-Domingo M, González-Sarmiento R. Early-onset type 2 diabetes mellitus is associated to HNF4A T130I polymorphism in families of central Spain. J Investig Med 2014; 62(8): 968-974

35. Plengvidhya N, Boonyasrisawat W, Chongjaroen N, Jungtrakoon P, Sriussadaporn S, Vannaseang S, Banchuin N, Yenchitsomanus PT. Mutations of maturity-onset diabetes of the young (MODY) genes in Thais with early-onset type 2 diabetes mellitus. Clin Endocrinol (Oxf) 2009; 70(6): 847-853

36. Domínguez-López A, Miliar-García A, Segura-Kato YX, Riba L, Esparza-López R, Ramírez-Jiménez S, Rodríguez-Torres M, Canizales-Quinteros S, Cabrera-Vásquez S, Fragoso-Ontiveros V, Aguilar-Salinas CA, Altamirano-Bustamante N, Calzada-León R, Robles-Valdés C, Bravo-Ríos LE, Tusié-Luna MT. Mutations in MODY genes are not common cause of early-onset type 2 diabetes in Mexican families. JOP 2005; 6(3): 238-245

37. Zhou S, Meng X, Wang S, Ren R, Hou W, Huang K, Shi H. A 3year follow-up study of $\beta$-cell function in patients with early-onset type 2 diabetes. Exp Ther Med 2016; 12(2): 1097-1102

38. Diabetes Control and Complications Trial Research Group, Nathan DM, Genuth S, Lachin J, Cleary P, Crofford O, Davis M, Rand L, Siebert C. The effect of intensive treatment of diabetes on the development and progression of long-term complications in insulindependent diabetes mellitus. N Engl J Med 1993; 329(14): 977-986

39. ADVANCE Collaborative Group, Patel A, MacMahon S, Chalmers
J, Neal B, Billot L, Woodward M, Marre M, Cooper M, Glasziou P, Grobbee D, Hamet P, Harrap S, Heller S, Liu L, Mancia G, Mogensen CE, Pan C, Poulter N, Rodgers A, Williams B, Bompoint $\mathrm{S}$, de Galan BE, Joshi R, Travert F. Intensive blood glucose control and vascular outcomes in patients with type 2 diabetes. N Engl J Med 2008; 358(24): 2560-2572

40. UK Prospective Diabetes Study (UKPDS) Group. Intensive bloodglucose control with sulphonylureas or insulin compared with conventional treatment and risk of complications in patients with type 2 diabetes (UKPDS 33). Lancet 1998; 352(9131): 837-853

41. Amutha A, Anjana RM, Venkatesan U, Ranjani H, Unnikrishnan R, Venkat Narayan KM, Mohan V, Ali MK. Incidence of complications in young-onset diabetes: comparing type 2 with type 1 (the young diab study). Diabetes Res Clin Pract 2017; 123: 1-8

42. Hessler DM, Fisher L, Mullan JT, Glasgow RE, Masharani U. Patient age: a neglected factor when considering disease management in adults with type 2 diabetes. Patient Educ Couns 2011; 85(2): 154-159

43. Wong MCS, Kong APS, So WY, Jiang JY, Chan JCN, Griffiths SM. Adherence to oral hypoglycemic agents in 26,782 Chinese patients: a cohort study. J Clin Pharmacol 2011; 51(10): 1474-1482

44. Yeung RO, Zhang Y, Luk A, Yang W, Sobrepena L, Yoon KH, Aravind SR, Sheu W, Nguyen TK, Ozaki R, Deerochanawong C, Tsang CC, Chan WB, Hong EG, Do TQ, Cheung Y, Brown N, Goh SY, Ma RC, Mukhopadhyay M, Ojha AK, Chakraborty S, Kong AP, Lau W, Jia W, Li W, Guo X, Bian R, Weng J, Ji L, Reyes-dela Rosa M, Toledo RM, Himathongkam T, Yoo SJ, Chow CC, Ho LL, Chuang LM, Tutino G, Tong PC, So WY, Wolthers T, Ko G, Lyubomirsky G, Chan JC. Metabolic profiles and treatment gaps in young-onset type 2 diabetes in Asia (the JADE programme): a crosssectional study of a prospective cohort. Lancet Diabetes Endocrinol 2014; 2(12): 935-943

45. Avignon A, Attali C, Sultan A, Ferrat E, Le Breton J. Clinical inertia: viewpoints of general practitioners and diabetologists. Diabetes Metab 2012; 38(Suppl 3): S53-S58

46. Kim KS, Oh HJ, Kim JW, Lee YK, Kim SK, Park SW, Kim YL, Park WK, Cho YW. The clinical characteristics of the newly diagnosed early onset $(<40$ years old) diabetes in outpatients' clinic. Korean Diabetes J 2010; 34(2): 119-125

47. Hatunic M, Burns N, Finucane F, Mannion C, Nolan JJ. Contrasting clinical and cardiovascular risk status between early and later onset type 2 diabetes. Diab Vasc Dis Res 2005; 2(2): 73-75

48. Saydah S, Bullard KM, Imperatore G, Geiss L, Gregg EW. Cardiometabolic risk factors among US adolescents and young adults and risk of early mortality. Pediatrics 2013; 131(3): e679e686

49. Li L, Ji L, Guo X, Ji Q, Gu W, Zhi X, Li X, Kuang H, Su B, Yan J, Yang X. Prevalence of microvascular diseases among tertiary care Chinese with early versus late onset of type 2 diabetes. J Diabetes Complications 2015; 29(1): 32-37

50. Katulanda P, Waniganayake YC, Ranasinghe P, Wijetunga WU, Jayaweera M, Wijesinghe NP, Sheriff R, Matthews DR. Retinopathy among young adults with diabetes mellitus from a tertiary care setting in Sri Lanka. BMC Endocr Disord 2014; 14(1): 20

51. Tryggestad JB, Willi SM. Complications and comorbidities of T2DM in adolescents: findings from the TODAY clinical trial. J Diabetes Complications 2015; 29(2): 307-312 
52. Sosale B, Sosale AR, Mohan AR, Kumar PM, Saboo B, Kandula S. Cardiovascular risk factors, micro and macrovascular complications at diagnosis in patients with young onset type 2 diabetes in India: CINDI 2. Indian J Endocrinol Metab 2016; 20(1): 114-118

53. Rajalakshmi R, Amutha A, Ranjani H, Ali MK, Unnikrishnan R, Anjana RM, Narayan KM, Mohan V. Prevalence and risk factors for diabetic retinopathy in Asian Indians with young onset type 1 and type 2 diabetes. J Diabetes Complications 2014; 28(3): 291-297

54. Bogdanović R. Diabetic nephropathy in children and adolescents. Pediatr Nephrol 2008; 23(4): 507-525

55. Ruhayel SD, James RA, Ehtisham S, Cameron FJ, Werther GA, Sabin MA. An observational study of type 2 diabetes within a large Australian tertiary hospital pediatric diabetes service. Pediatr Diabetes 2010; 11(8): 544-551

56. Eppens MC, Craig ME, Cusumano J, Hing S, Chan AK, Howard NJ, Silink M, Donaghue KC. Prevalence of diabetes complications in adolescents with type 2 compared with type 1 diabetes. Diabetes Care 2006; 29(6): 1300-1306

57. Scott A, Toomath R, Bouchier D, Bruce R, Crook N, Carroll D, Cutfield R, Dixon P, Doran J, Dunn P, Hotu C, Khant M, Lonsdale M, Lunt H, Wiltshire E, Wu D. First national audit of the outcomes of care in young people with diabetes in New Zealand: high prevalence of nephropathy in Maori and Pacific Islanders. N Z Med J 2006; 119(1235): U2015

58. Maahs DM, Snively BM, Bell RA, Dolan L, Hirsch I, Imperatore G, Linder B, Marcovina SM, Mayer-Davis EJ, Pettitt DJ, Rodriguez BL, Dabelea D. Higher prevalence of elevated albumin excretion in youth with type 2 than type 1 diabetes: the SEARCH for Diabetes in Youth study. Diabetes Care 2007; 30(10): 2593-2598

59. Strong JP, Malcom GT, McMahan CA, Tracy RE, Newman WP 3rd, Herderick EE, Cornhill JF. Prevalence and extent of atherosclerosis in adolescents and young adults: implications for prevention from the Pathobiological Determinants of Atherosclerosis in Youth Study. JAMA 1999; 281(8): 727-735

60. Constantino MI, Molyneaux L, Limacher-Gisler F, Al-Saeed A, Luo $\mathrm{C}$, Wu T, Twigg SM, Yue DK, Wong J. Long-term complications and mortality in young-onset diabetes: type 2 diabetes is more hazardous and lethal than type 1 diabetes. Diabetes Care 2013; 36 (12): 3863-3869

61. Chan JC, Lau ES, Luk AO, Cheung KK, Kong AP, Yu LW, Choi KC, Chow FC, Ozaki R, Brown N, Yang X, Bennett PH, Ma RC, So WY. Premature mortality and comorbidities in young-onset diabetes: a 7-year prospective analysis. Am J Med 2014; 127(7): 616-624
62. Contreras-Rodríguez A, Gómez-Díaz RA, Tanus-Hajj J, Talavera JO, Mondragón-González R, Wacher NH. Carotid intima-media thickness, ankle-arm index, and inflammation profile in Mexican patients with early and late onset type 2 diabetes. Rev Invest Clin 2015; 67(4): 240-249

63. Wannamethee SG, Shaper AG, Whincup PH, Lennon L, Sattar N. Impact of diabetes on cardiovascular disease risk and all-cause mortality in older men: influence of age at onset, diabetes duration, and established and novel risk factors. Arch Intern Med 2011; 171 (5): 404-410

64. TODAY Study Group, Zeitler P, Hirst K, Pyle L, Linder B, Copeland K, Arslanian S, Cuttler L, Nathan DM, Tollefsen S, Wilfley D, Kaufman F. A clinical trial to maintain glycemic control in youth with type 2 diabetes. N Engl J Med 2012; 366(24): 22472256

65. Jones KL, Arslanian S, Peterokova VA, Park JS, Tomlinson MJ. Effect of metformin in pediatric patients with type 2 diabetes: a randomized controlled trial. Diabetes Care 2002; 25(1): 89-94

66. Gottschalk M, Danne T, Vlajnic A, Cara JF. Glimepiride versus metformin as monotherapy in pediatric patients with type 2 diabetes: a randomized, single-blind comparative study. Diabetes Care 2007; 30(4): 790-794

67. Yan F, Cha E, Lee ET, Mayberry RM, Wang W, Umpierrez G. A self-assessment tool for screening young adults at risk of type 2 diabetes using Strong Heart Family Study Data. Diabetes Educ 2016; 42(5): 607-617

68. Orozco LJ, Buchleitner AM, Gimenez-Perez G, Roqué I Figuls M, Richter B, Mauricio D. Exercise or exercise and diet for preventing type 2 diabetes mellitus. Cochrane Database Syst Rev 2008; 16(3): CD003054

69. Merlotti C, Morabito A, Pontiroli AE. Prevention of type 2 diabetes; a systematic review and meta-analysis of different intervention strategies. Diabetes Obes Metab 2014; 16(8): 719-727

70. Knowler WC, Barrett-Connor E, Fowler SE, Hamman RF, Lachin JM, Walker EA, Nathan DM; Diabetes Prevention Program Research Group. Reduction in the incidence of type 2 diabetes with lifestyle intervention or metformin. N Engl J Med 2002; 346 (6): 393-403

71. Amutha A, Mohan V. Diabetes complications in childhood and adolescent onset type 2 diabetes - a review. J Diabetes Complications 2016; 30(5): 951-957

72. Rosenbloom AL, Silverstein JH, Amemiya S, Zeitler P, Klingensmith GJ. Type 2 diabetes in children and adolescents. Pediatr Diabetes 2009; 10(Suppl 12): 17-32 